\title{
Sexual Behavior and Sex-Associated Environmental Cues Activate the Mesolimbic System in Male Rats
}

\author{
Margaret E Balfour', Lei Yu' and Lique M Coolen*,' \\ 'Neuroscience Graduate Program, Department of Cell Biology, Neurobiology and Anatomy, University of Cincinnati College of Medicine, \\ Cincinnati, $\mathrm{OH}$, USA
}

\begin{abstract}
The mesolimbic system plays an important role in the regulation of both pathological behaviors such as drug addiction and normal motivated behaviors such as sexual behavior. The present study investigated the mechanism by which this system is endogenously activated during sexual behavior. Specifically, the effects of sexual experience and sex-related environmental cues on the activation of several components of the mesolimbic system were studied. The mesolimbic system consists of a dopaminergic projection from the ventral tegmental area (VTA) to the nucleus accumbens (NAc). Previous studies suggest that these neurons are under tonic inhibition by local GABA interneurons, which are in turn modulated by mu opioid receptor (MOR) ligands. To test the hypothesis that opioids are acting in the VTA during sexual behavior, visualization of MOR internalization in VTA was used as a marker for ligand-induced activation of the receptor. Significant increases in MOR internalization were observed following copulation or exposure to sex-related environmental cues. The next goal was to determine if sexual behavior activates dopamine neurons in the VTA, using tyrosine hydroxylase as a marker for dopaminergic neurons and Fos-immunoreactivity as a marker for neuronal activation. Significant increases in the percentage of activated dopaminergic neurons were observed following copulation or exposure to sex-related environmental cues. In addition, mating and sex-related cues activated a large population of nondopaminergic neurons in VTA as well as neurons in both the NAc Core and Shell. Taken together, our results provide functional neuroanatomical evidence that the mesolimbic system is activated by both sexual behavior and exposure to sex-related environmental cues.
\end{abstract}

Neuropsychopharmacology (2004) 29, 7I8-730, advance online publication, 23 December 2003; doi: 10.1038/sj.npp. I 300350

Keywords: ventral tegmental area; nucleus accumbens; dopamine; mu opioid receptor; endocytosis; GABA; sexual behavior; Fos

\section{INTRODUCTION}

The mesolimbic dopamine system is a key component of the neural circuitry regulating motivation and reward. This system can be activated via exogenous application of drugs of abuse, often resulting in a pathological set of behaviors known as addiction. However, the mesolimbic system also plays a major role in the regulation of normal motivated behaviors such as feeding, drinking, aggression, and sexual behavior. While numerous studies have focused on druginduced activation of this pathway, less is known about the function of the mesolimbic system under natural conditions. Therefore, the present study investigates the en-

\footnotetext{
*Correspondence: Dr LM Coolen, Department of Cell Biology, Neurobiology and Anatomy, University of Cincinnati College of Medicine, Vontz Center for Molecular Studies, 3125 Eden Ave., Cincinnati, OH 45267-052I, USA, Tel: + 513558 I209, Fax: + 513 558 4454, E-mail: Lique.Coolen@uc.edu

Received 08 August 2003; revised 06 October 2003; accepted 09 October 2003

Online Publication: 10 October 2003 at http://www.acnp.org/citations/ Npp I010030336I/default.pdf
}

dogenous mechanisms by which sexual behavior activates the mesolimbic dopamine system.

Male rodent sexual behavior consists of an appetitive approach phase followed by a consummatory phase in which the animal mounts and intromits, culminating with ejaculation (Hull et al, 2002). Behavioral studies indicate that male rodent sexual behavior - and in particular ejaculation - is a rewarding and reinforcing behavior. Male rats readily develop a conditioned place preference to copulation (Agmo and Berenfeld, 1990; Agmo and Gomez, 1993; Meisel et al, 1996; Paredes and Alonso, 1997; Lopez et al, 1999; Martinez and Paredes, 2001), and will perform operant tasks to gain access to a sexually receptive female (Everitt et al, 1987; Everitt and Stacey, 1987).

The mesolimbic dopamine system, consisting of dopamine (DA) producing neurons located in the ventral tegmental area (VTA) that project to the nucleus accumbens (NAc), plays a critical role in the motivated and rewarding aspects of sexual behavior. Microdialysis studies have indicated that dopamine is released into the NAc upon presentation of the female, and remains elevated throughout the display of sexual behavior (Pfaus et al, 1990; Pfaus and Phillips, 1991; Damsma et al, 1992; Wenkstern et al, 1993). 
Furthermore, infusion of DA receptor agonists into the NAC facilitates the initiation of sexual behavior in male rats (Everitt et al, 1989), while antagonists have inhibitory effects (Pfaus and Phillips, 1989). The dopaminergic projection neurons in the VTA are likely under tonic inhibition by local GABAergic interneurons. Stimulation of the $G_{i / o}$-coupled mu opioid receptor (MOR) results in the inhibition of these GABAergic neurons, which in turn leads to disinhibition of dopaminergic projection neurons and the subsequent release of DA into NAc. This circuitry model is supported by multiple electrophysiological and pharmacological studies (Matthews and German, 1984; Johnson and North, 1992; Klitenick et al, 1992; Ikemoto et al, 1997), and is illustrated in Figure 1. We hypothesize that, during sexual behavior, endogenous opioids are released into the VTA, resulting in disinhibition of dopaminergic projection neurons. This hypothesis is supported by studies demonstrating that opioid antagonists infused into the VTA inhibit sexual motivation (van Furth and van Ree, 1996). The current study consists of a set of experiments designed to provide neuroanatomical evidence for this model.

The first goal of this study is to extend our knowledge of the anatomical distribution of MOR in the VTA, particularly with respect to GABAergic neurons. Despite the wealth of pharmacological data, relatively little is known about the anatomical organization of this circuitry. It has been demonstrated that MOR are primarily present in nondopaminergic neurons in the VTA (Garzon and Pickel, 2001). However, it is unknown if MOR are located on GABA neurons.

The overall goal of the present study is to investigate the activation of the MOR and DA neurons in the VTA during male sexual behavior. First, to test the hypothesis that opioids are released into the VTA during sexual behavior, we used MOR internalization as a marker for ligandinduced activation of the receptor. This technique takes advantage of the fact that G-protein-coupled receptors undergo endocytosis following ligand binding. In particular, MORs have been shown to undergo ligand-induced endocytosis both in vitro (Keith et al, 1998) as well as in vivo (Eckersell et al, 1998; Trafton et al, 2000; Sinchak and Micevych, 2001). Internalized endosome-like particles can be visualized using confocal microscopy, and quantification of these particles provides an indirect measure of endogenous opioid peptide release. In addition, this technique allows cellular resolution in the determination of the targets of endogenous opioid action. Our next goal was to

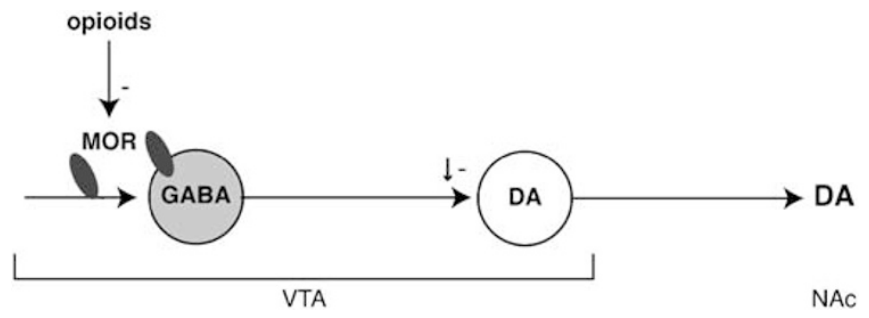

Figure I Proposed circuitry model of mesolimbic activation during sexual behavior. In this model, endogenous opioid peptides are released into the VTA and bind to MORs, inhibiting GABAergic interneurons. This releases the dopaminergic projection neurons from inhibition, resulting in $D A$ release into the NAc. determine if sexual behavior activates DA neurons in the VTA. To address this question, we used Fos immunoreactivity (Fos-IR) as a marker of neuronal activation. Finally, to assess whether the NAc is activated during sexual behavior, we quantified Fos-IR in both the NAc Core and Shell subregions.

Experience and environment also play an important role in the activation of the mesolimbic system. In humans, drug addicts often report intense bouts of craving following exposure to drug-associated environmental cues (Childress et al, 1988; Wallace, 1989). In rodents, exposure to drugassociated cues leads to conditioned activation of the mesolimbic dopamine system, which is evidenced by increased DA release (Duvauchelle et al, 2000) and immediate early gene expression in the NAc (Ostrander et al, 2003) following exposure to a drug-paired environment. Less is known about conditioned responses to environmental cues associated with normal motivated behaviors such as sexual behavior. Sexually experienced male rats display increases in NAc DA when exposed to an estrous female behind a wire mesh (Damsma et al, 1992). However, exposure to bedding soiled by an estrous female also stimulates DA release in the NAc (Mitchell and Gratton, 1991), and it is unknown whether conditioned activation of the mesolimbic system is dependent on olfactory input. Therefore, a major goal of the present study is to determine if sex-associated spatial and tactile cues activate the mesolimbic system, in the absence of olfactory input. Specifically, we used the methods described above to compare sex-induced activation of the mesolimbic system in animals that are sexually experienced $v s$ naïve animals. In addition, we compared animals that gained their experience in different environments, in order to investigate the effect of sex-related environmental cues on the activation of the mesolimbic DA system.

\section{MATERIALS AND METHODS}

\section{Animals}

Adult male Sprague-Dawley rats (250-260 g) were obtained from Harlan (Indianapolis, IN) and housed individually in Plexiglas cages for the duration of the experiment. The colony room was maintained on $12 / 12 \mathrm{~h}$ reversed light-dark cycle (lights off at $1000 \mathrm{~h}$ ). Food and water were available ad libitum. Stimulus females for mating behavior tests were bilaterally ovariectomized and received a subcutaneous implant containing 5\% estradiol benzoate (EB) and $95 \%$ cholesterol. Sexual receptivity was induced by administration of $500 \mu \mathrm{g}$ progesterone (subcutaneous) in $0.1 \mathrm{ml}$ sesame oil, $5 \mathrm{~h}$ before testing. All procedures were approved by the Animal Care and Use Committee of the University of Cincinnati, and conformed to NIH guidelines involving vertebrate animals in research.

\section{Sexual Behavior}

Eight experimental groups were included in this experiment (see Table 1). These groups differed in sexual experience (naïve $v s$ experienced), the environment in which sexual behavior testing was performed (home cage $v s$ test cage), and the behavior on the final test day ( $\operatorname{sex} v s$ unmated 
Table I Overview of Experimental Groups

Group Sexual experience Test environment Final test behavio

\begin{tabular}{llll}
\hline 1 & Naive & Home cage & Control (no sex) \\
2 & Naive & Home cage & Sex \\
3 & Experienced & Home cage & Control (no sex) \\
4 & Experienced & Home cage & Sex \\
5 & Naive & Test cage & Control (no sex) \\
6 & Naive & Test cage & Sex \\
7 & Experienced & Test cage & Control (no sex) \\
8 & Experienced & Test cage & Sex \\
\hline
\end{tabular}

An overview of the eight experimental groups used in the current study is presented. The groups differ in three factors: sexual experience (naive vs experienced); the environment in which the animals gained experience (home cage vs test cage); the behavior on the final test day (unmated control vs sex).

control). First, the animals were divided into four groups differing in sexual experience and the environment in which they were tested. The environment consisted of the home cage or a test cage. The home cage refers to the standard Plexiglas cages in which the animals were individually housed for the duration of the experiment. The test cage refers to a cage different from the home cage, that is, larger and without odor cues $\left(60 \times 45 \times 50 \mathrm{~cm}^{3}\right)$, in which the animals were placed during each test session (see below). This test cage was thoroughly cleaned with alcohol solution (70\%) between sessions, and contained clean bedding. Animals in the sexually experienced groups were allowed to mate with a receptive female to one ejaculation or for $60 \mathrm{~min}$, whichever came first, during five twice-weekly pretest sessions. During these pre-test sessions, animals either mated in their home cages or in the larger test cage with clean bedding. The animals that gained sexual experience in the test cage were placed in the test cage for $60 \mathrm{~min}$ prior to the introduction of the female, and then allowed to mate to one ejaculation or $60 \mathrm{~min}$. Males that gained sexual experience in the home cage received a receptive female in the home cage and were allowed to mate to one ejaculation or for $60 \mathrm{~min}$. At 1 week following the last pretest mating session, the sexually experienced rats were randomly subdivided into mated ('sex') and unmated ('control') groups (total of four sexually experienced groups, $N=4$ each). During the final test, 'sex' animals were allowed to mate to one ejaculation in the same environment in which they gained experience, that is, home or test cage. Thus, animals that gained sexual experience in the home cages remained in the home cage, received a receptive female, and mated to one ejaculation. Animals that gained sexual experience in the test cage were placed in the test cages for $1 \mathrm{~h}$, following which a female was placed in the test cage and the males mated to one ejaculation. At 5 min following ejaculation, the female partner was removed and the male remained in the home cage or test cage for $1 \mathrm{~h}$ until sacrifice. Control animals did not receive a receptive female partner on the final test day, but instead were taken from the home cage or were placed in the test cage without a receptive female for $2 \mathrm{~h}$ before sacrifice, depending on the environment in which they gained sexual experience.
Sexually naive animals (animals that did not receive sexual experience) were either left undisturbed in the home cage or were placed in the test cages without a female for $1 \mathrm{~h}$ for five twice-weekly sessions. At 1 week following the last pre-test session, the rats were randomly subdivided into 'sex' and 'control' groups (total of four sexually naïve groups, $N=4$ each). Similar to the sexually experienced groups, the environment in which the final test was conducted was the same as during the pre-test sessions. Hence, the naïve males exposed to the test cage during the pre-test sessions were placed in the test cages for $1 \mathrm{~h}$, following which a female was placed in the test cage and the males mated to one ejaculation ('sex') or were placed in the test cage without a receptive female for $2 \mathrm{~h}$ (unmated control). Males that remained in the home cages either received a receptive female and mated to one ejaculation ('sex'), or were killed from the home cage (unmated control). In the 'sex' groups, the female partner was removed $5 \mathrm{~min}$ following ejaculation, and the males remained in the home cage or test cage for $1 \mathrm{~h}$ until sacrifice.

\section{Tissue Preparation}

The animals were deeply anesthetized using pentobarbital $(200 \mathrm{mg} / \mathrm{kg})$, and perfused transcardially with $100 \mathrm{ml}$ of $0.9 \% \mathrm{NaCl}$ followed by $500 \mathrm{ml}$ of $4 \%$ paraformaldehyde, in $0.1 \mathrm{M}$ phosphate buffer ( $\mathrm{PB} ; \mathrm{pH}$ 7.3). The brains were removed and post-fixed for $1 \mathrm{~h}$ at room temperature in the fixative, then placed in $20 \%$ sucrose in $0.1 \mathrm{M} \mathrm{PB}$ and stored at $4^{\circ} \mathrm{C}$. Coronal sections $(35 \mu \mathrm{m})$ were cut on a freezing microtome (Richard Allen, Kalamazoo, MI), collected in four parallel series in cryoprotectant solution (30\% sucrose, $30 \%$ ethylene glycol in $0.1 \mathrm{M} \mathrm{PB}$; Watson et al, 1986), and stored at $-20^{\circ} \mathrm{C}$ until further processing.

\section{Immunocytochemistry}

All incubations were performed at room temperature with gentle agitation. The free-floating sections were washed extensively with $0.1 \mathrm{M}$ phosphate-buffered saline (PBS) between incubations. Sections were incubated for $10 \mathrm{~min}$ with $1 \% \mathrm{H}_{2} \mathrm{O}_{2}$, then blocked for $1 \mathrm{~h}$ with incubation solution (PBS containing $0.1 \%$ bovine serum albumin and $0.4 \%$ triton X-100). All primary antibody incubations were performed in the incubation solution, overnight at room temperature. Following staining, the sections were washed thoroughly in $0.1 \mathrm{M} \mathrm{PB}$, mounted onto glass slides with $0.3 \%$ gelatin in $\mathrm{dd}_{2} \mathrm{O}$ and coverslipped with DPX (Electron Microscopy Sciences, Fort Washington, PA) or an aqueous mounting medium (Gelvatol) containing an anti-fading agent 1,4-diazabicyclo(2,2)octane (DABCO; $50 \mathrm{mg} / \mathrm{ml}$, Sigma-Aldrich, St. Louis, MO), prepared as described previously (Harlow and Lane, 1988). Immunocytochemical controls included omission of primary antibodies. VTA and/or NAc series were stained for the following markers:

Fos/TH. VTA and NAc sections were incubated overnight with a rabbit polyclonal antibody to c-Fos (1:7500; SC-52; Santa Cruz Biotechnology, Santa Cruz, CA) followed by one hour incubations with biotinylated donkey anti-rabbit IgG (1:400; Jackson ImmunoResearch Laboratories, West 
Grove, PA) and avidin-horseradish peroxidase complex (1:1000; ABC Elite Kit, Vector Laboratories, Burlingame, CA). Finally, the sections were incubated for $10 \mathrm{~min}$ in $0.02 \%$. diaminobenzidine (DAB; Sigma-Aldrich, St Louis, $\mathrm{MO}$ ) in $0.1 \mathrm{M} \mathrm{PB}$ containing $0.012 \%$ hydrogen peroxide and $0.08 \%$ nickel sulfate, resulting in a blue-black reaction product. Next, VTA sections were incubated overnight with mouse monoclonal antibody to tyrosine hydroxylase (TH; 1:400000; Chemicon International, Temecula, CA), biotinylated donkey anti-mouse IgG secondary antibody ( $1: 400$; Jackson ImmunoResearch Laboratories, West Grove, PA) and $\mathrm{ABC}$ as described above. Finally, the sections were incubated for $10 \mathrm{~min}$ in $0.02 \% \mathrm{DAB}$ in $0.1 \mathrm{M}$ $\mathrm{PB}$ containing $0.012 \%$ hydrogen peroxide, resulting in a reddish-brown reaction product.

MOR. VTA sections were incubated overnight with a rabbit polyconal antibody recognizing the C-terminal region of the rat MOR1 (1:10000; DiaSorin, Saluggia, Italy), biotinylated donkey anti-rabbit IgG and ABC, as described above. Next, the sections were incubated for $10 \mathrm{~min}$ with biotinylated tyramide (BT; $1: 250$ in PBS $+0.003 \% \mathrm{H}_{2} \mathrm{O}_{2}$; Tyramide Signal Amplification Kit, NEN Life Sciences, Boston, MA) and for $30 \mathrm{~min}$ with $\mathrm{CY}-3$ conjugated steptavidin (1:200; Jackson ImmunoResearch Laboratories, West Grove, PA).

$G A B A / M O R$. VTA sections were incubated overnight with a mouse monoclonal antibody to GABA (1:1000 in PBS/BSA without TX; Sigma-Aldrich, St Louis, MO) and for $30 \mathrm{~min}$ with goat anti-mouse IgG conjugated to Alexa 488 (1:200 in PBS/BSA; Jackson ImmunoResearch Laboratories, West Grove, PA). The sections were then stained for MOR, as described above.

$G A D / T H$. VTA sections were incubated with a rabbit polyclonal antibody recognizing glutamic acid decarboxylase (GAD; 1:1500, Chemicon International, Temecula, $\mathrm{CA}$ ), followed by incubations with biotinylated donkey antirabbit IgG, $\mathrm{ABC}, \mathrm{BT}$, and $\mathrm{CY}-3$-conjugated streptavidin, as described above. Next, sections were incubated with a mouse monoclonal antibody to tyrosine hydroxylase (TH; $1: 40$ 000; Chemicon International, Temecula, CA), followed by a 30-min incubation with goat anti-mouse IgG conjugated to Alexa 488 (1:200; Jackson ImmunoResearch Laboratories, West Grove, PA).

\section{Data Analysis}

VTA anatomy. For anatomical analysis of the VTA, stacks of $1 \mu \mathrm{m}$ optical sections were captured along the $z$-axis, using a Zeiss LSM-510 laser-scanning microscope. CY3fluorescence was imaged with a $567 \mathrm{~nm}$ emission filter and a $\mathrm{He}-\mathrm{Ne}$ laser, and Alexa 488 with $505 \mathrm{~nm}$ emission filter and argon laser. The distribution of GAD-IR fibers relative to $\mathrm{TH}$ neurons was investigated. In addition, the location of MOR in relation to GABA-IR cell bodies was investigated and the rostrocaudal distribution of MOR-IR neurons co-expressing GABA was quantified in one animal. In addition, the rostrocaudal distribution on MOR-IR cell bodies throughout the VTA was analyzed in three animals.
Sexual behavior. Each pre-test and final test mating session was observed and sexual behavior was recorded: number of mounts $(\# \mathrm{M})$, number of intromissions (\#I), mount and intromission latencies (ML and IL, ie the time from presentation of the female to the first mount or intromission), and ejaculation latency (EL; the time from the first intromission to ejaculation). Results of each measure for the last day of the pre-test mating sessions were analyzed using a one-way ANOVA, to determine if the mating environment (home cage $v s$ test cage) affected sexual experience. Results from the final test day were analyzed using a two-way ANOVA (factors: experience, environment) and post hoc comparisons were performed using Fisher's PLSD, all with $5 \%$ significance levels.

MOR internalization. For quantitative analysis of endosome counts in VTA neurons, $z$-stacks of $1 \mu \mathrm{m}$ optical sections through 15-30 neurons were captured using a Zeiss laser-scanning confocal microscope system (Zeiss LSM510). Of each stack of images through the neurons, two consecutive sections in the middle of the neuron were used for analysis. Numbers of immunoreactive intracellular particles were counted for each cell by an observer blind to the experimental group, and were averaged per animal. In addition, the percentage of internalized MOR-IR cells was quantified; MOR-IR neurons containing three or more immunoreactive intracellular particles were considered internalized. Results were analyzed using a three-way ANOVA (factors: mating, experience, and environment) and post hoc comparisons (Fisher's PLSD) using 5\% significance levels. Images were imported into Adobe Photoshop 7.0 (Adobe Systems, San Jose, CA) to compose the figures. Images were not adjusted or altered in any way, except for brightness.

Fos/TH. Using a drawing tube attached to a Leica microscope (Leica Microsystems; Wetzlar, Germany), camera lucida drawings were made of the analyzed sections from each animal. In the VTA, camera lucida drawings were made of four sections approximately $280 \mu \mathrm{m}$ apart, representative of four rostral to caudal levels in the VTA (Figure 2). Using TH staining and the location of the medial lemniscus (ml) and fasciculus retroflexus (fr) as landmarks, standard areas were defined in which to count Fos-IR nuclei and Fos/TH double-labeled cells. Cell counts were performed in standard areas ranging from $2.16 \mathrm{~mm}^{2}$ (rostral and two middle levels) to $1.6 \mathrm{~mm}^{2}$ (most caudal level). In the NAc, camera lucida drawings were made of three sections approximately $600 \mu \mathrm{m}$ apart, representative of three rostral-to-caudal levels in the NAc (Figure 3). At each level, standard areas of $0.24 \mathrm{~mm}^{2}$ were defined, in which to count Fos-IR nuclei in both the NAc Core and NAc Shell. Group means were calculated for each separate rostral-tocaudal level in both NAc and VTA. In addition, an average of the four (VTA) or three (NAc) rostral-to-caudal levels were calculated per animal, and group means were based on animal averages. Results were analyzed using a three-way ANOVA (factors: mating, experience, and environment) and post hoc comparisons (Fisher's PLSD) using 5\% significance levels. Specifically, comparisons were made within each rostrocaudal level between: (1) each sex group and the corresponding control group, (2) all control groups, 

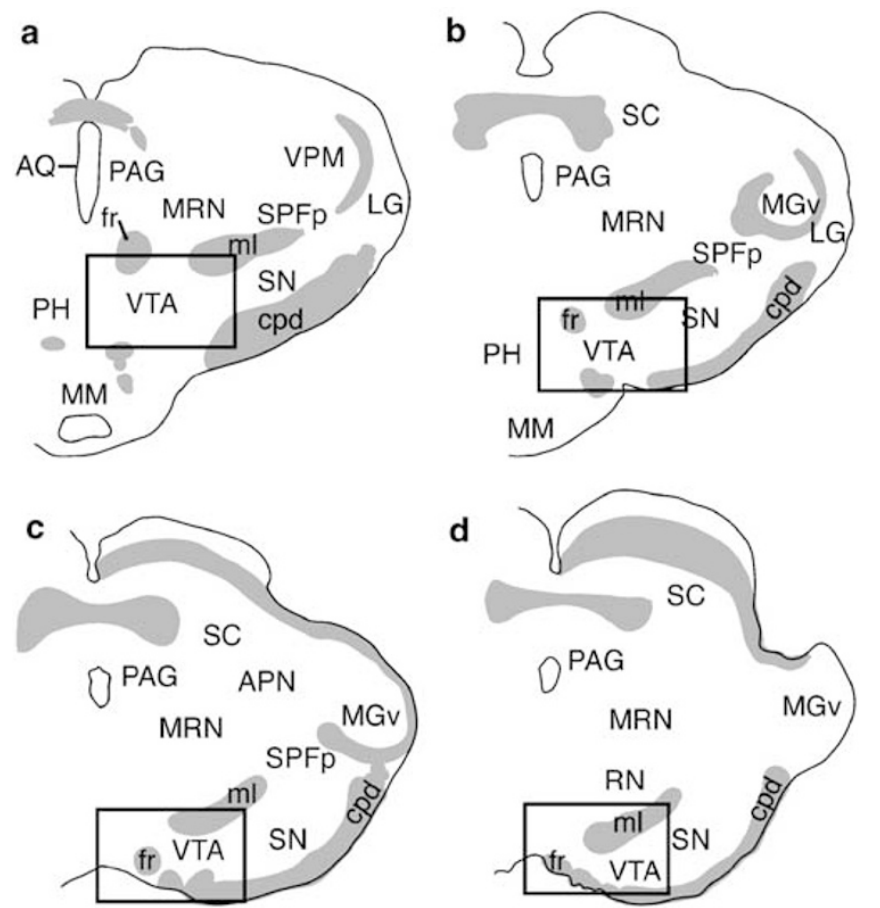

d

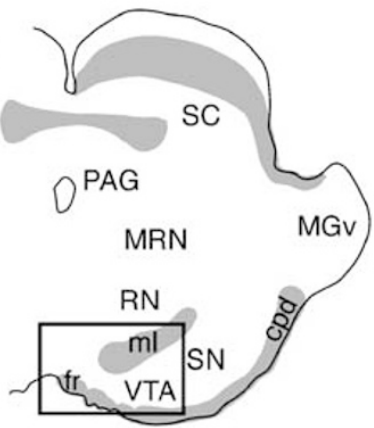

Figure 2 Schematic drawings illustrating the areas of analysis of Fos/TH$I R$, indicated by the boxes, in the VTA at four rostral to caudal levels. (a) Rostral, area of analysis $=1.8 \mathrm{~mm} \times 1.2 \mathrm{~mm}$. (b) Middle- I, area of analysis $=1.8 \mathrm{~mm} \times 1.2 \mathrm{~mm}$. (c) Middle-2, area of analysis $=1.8 \mathrm{~mm} \times 1.2 \mathrm{~mm}$. (d) Caudal, area of analysis $=1.6 \mathrm{~mm} \times 1.0 \mathrm{~mm}$. Abbreviations: $\mathrm{AQ}$, cerebral aqueduct; $\mathrm{PAG}$, periaquaductal gray; $\mathrm{fr}$, fasiculus retroflexus; ml, medial lemniscus; cpd, cerebral peduncle; SN, substantia nigra; LG, lateral geniculate complex; SPFp, subparafasicular nucleus thalamus parvicellular part; VPM, ventral posteriomedial nucleus thalamus; $\mathrm{PH}$, posterior hupothalamic nucleus; MRN, mesencephalic reticular nucleus; MGv, medial geniculate complex ventral part; APN, anterior pretectal nucleus; SC, superior colliculus; MM, medial mammillary nucleus.

and (3) all sex groups. Digital images of immunostained sections were captured using a digital camera (Magnafire, Optronics) attached to a Leica microscope (Leica Microsystems; Wetzlar, Germany). Images were imported into Adobe Photoshop 7.0 (Adobe Systems, San Jose, CA) to compose the figures. Images were not adjusted or altered in any way, except for occasional adjustment of brightness.

\section{RESULTS}

\section{VTA Anatomy}

MOR-IR was observed on both axon terminals and cell bodies (Figure 4a), and in fibers in close apposition to GABA-IR neurons. In addition, MOR-IR was observed to colocalize with GABA-IR in cell bodies (Figure 4a). Approximately $79 \%$ of MOR-IR neurons coexpressed GABA-IR in the rostral portion of the VTA where the majority of MOR-IR neurons are located. Few MOR-IR neurons were observed in the caudal VTA, although approximately $50 \%$ of these MORIR neurons co-express GABA. In addition, we observed GADIR fibers in close apposition to TH-IR neurons throughout the VTA (Figure $4 \mathrm{~b}$ ).
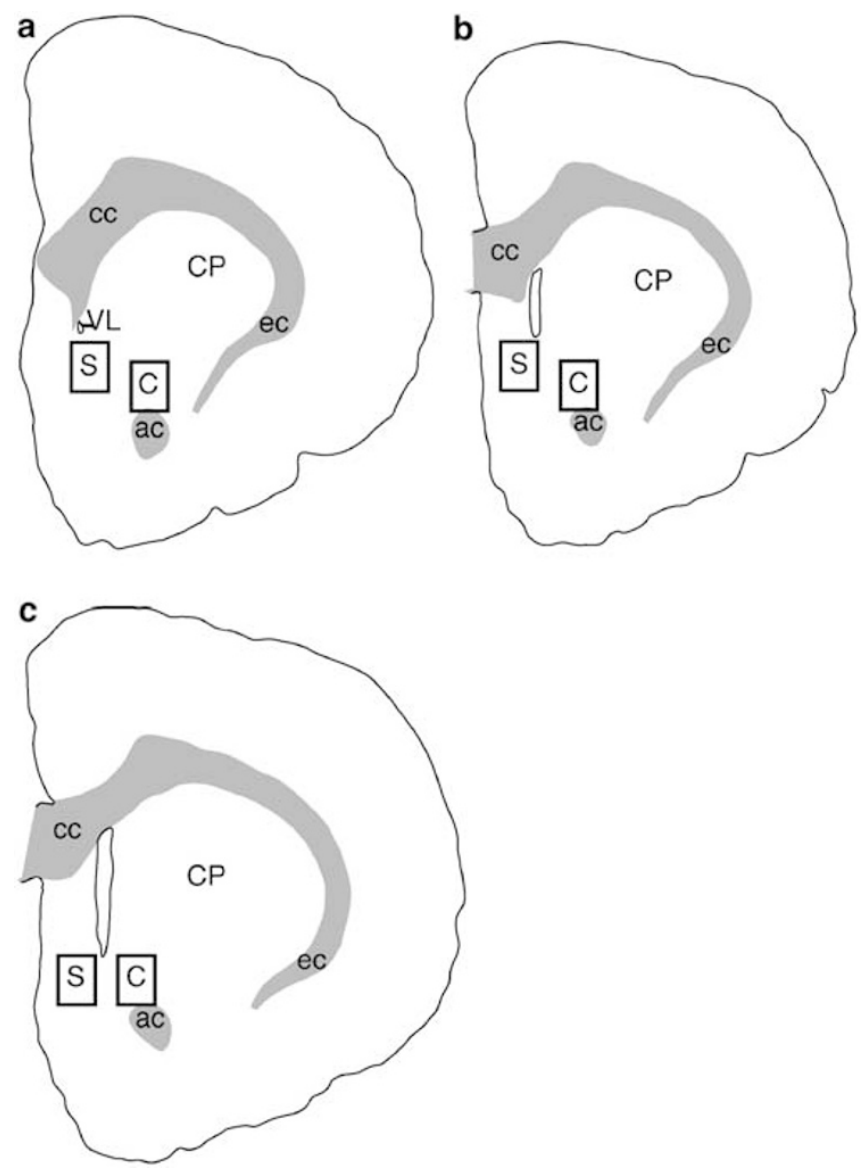

Figure 3 Schematic drawings illustrating the areas of analysis (indicated by the boxes) of Fos-IR in the NAc core and shell at three rostral-to-caudal levels $(\mathrm{a}-\mathrm{c})$. Area of analysis $=400 \mu \mathrm{m} \times 600 \mu \mathrm{m}$. Abbreviations: C, NAc core; S, NAc shell; VL, lateral ventricle; ac, anterior commissure; cc, corpus callosum; ec, external capsule; CP, caudate putamen.

\section{Sexual Behavior}

Measurements for sexual behavior on the last day of the pre-test mating sessions of the sexually experienced males are illustrated in Table 2. The environment in which the experienced males gained their experience did not affect any of the analyzed parameters of sexual behavior (Table 2). In particular, on the last day of the pre-test mating sessions, there were no differences between the males that mated in the home cage or in the test cage. Measurements for sexual behavior during the test day are illustrated in Table 3 . Significant differences were observed between the naïve and experienced males on the test day $\left(\mathrm{F}_{(1,12)}=8.927\right.$; $p=0.0113$; Table 3 ). Naïve males that mated in the test cage had higher numbers of mounts and longer latencies to mount, intromission, and ejaculation compared to experienced males that mated either in the test cage or in the home cage. We observed a similar trend in the naïve males that mated in the home cage, although the differences did not reach significance in post hoc tests. Statistically significant differences in sexual behavior between naïve males that mated in home $v s$ test cage were only observed in IL, which was higher in naïve males that mated in the test cage. 


\section{MOR Internalization}

Mating-induced internalization of MOR was analyzed in neurons located in the rostral VTA (Figure $4 \mathrm{c}, \mathrm{d}$ ), where the majority of MOR-IR cell bodies were located. Sexual behavior significantly increased MOR internalization in
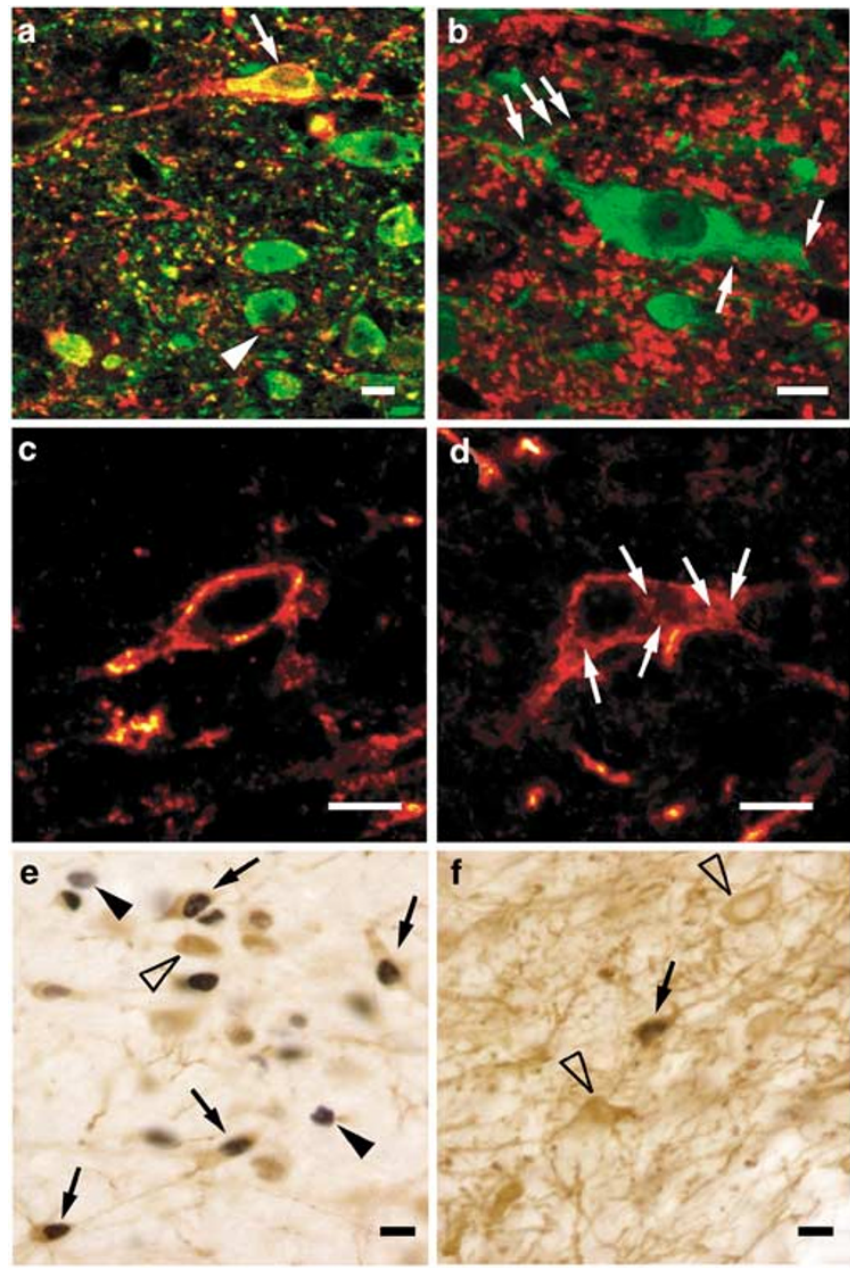

Figure 4 (a) Confocal image illustrating MOR (red) located on GABA-IR (green) cell bodies (arrow) and MOR-IR fibers in close apposition to GABA-IR cells (triangle) in the VTA. (b) Confocal image illustrating GAD-IR fibers (red) in close apposition to TH-IR (green) cells in the VTA. (c) Confocal image illustrating MOR-IR in the VTA of a nonmated control animal. (d) Confocal image illustrating MOR-IR in the VTA of a mated animal. Arrows indicate MOR-IR endosome like particles. Confocal images in (b-d) are I $\mu \mathrm{m}$ optical sections, and image (a) is a $5 \mu \mathrm{m}$ optical section. (e,f) Photomicrographs illustrating Fos-IR (black, filled triangle) and TH-IR (brown, open triangle) in the VTA. Double-labeled cells are indicated by arrows. Scale bars indicate $10 \mu \mathrm{m}$ the VTA $\left(\mathrm{F}_{(1,23)}=112.382 ; p<0.0001\right)$. Significant matinginduced increases in the number of MOR-IR endosome-like particles were observed in all males that mated on the test day, compared to their controls (Figure 5a, filled $v s$ open bars; $p<0.03$ ). In addition, exposure to the sex-related environment alone also resulted in a significant increase of MOR internalization. In particular, a three-way interaction between mating, experience, and environment was observed $\left(\mathrm{F}_{(123)}=16.370 ; p=0.0005\right)$ and post hoc analysis indicated
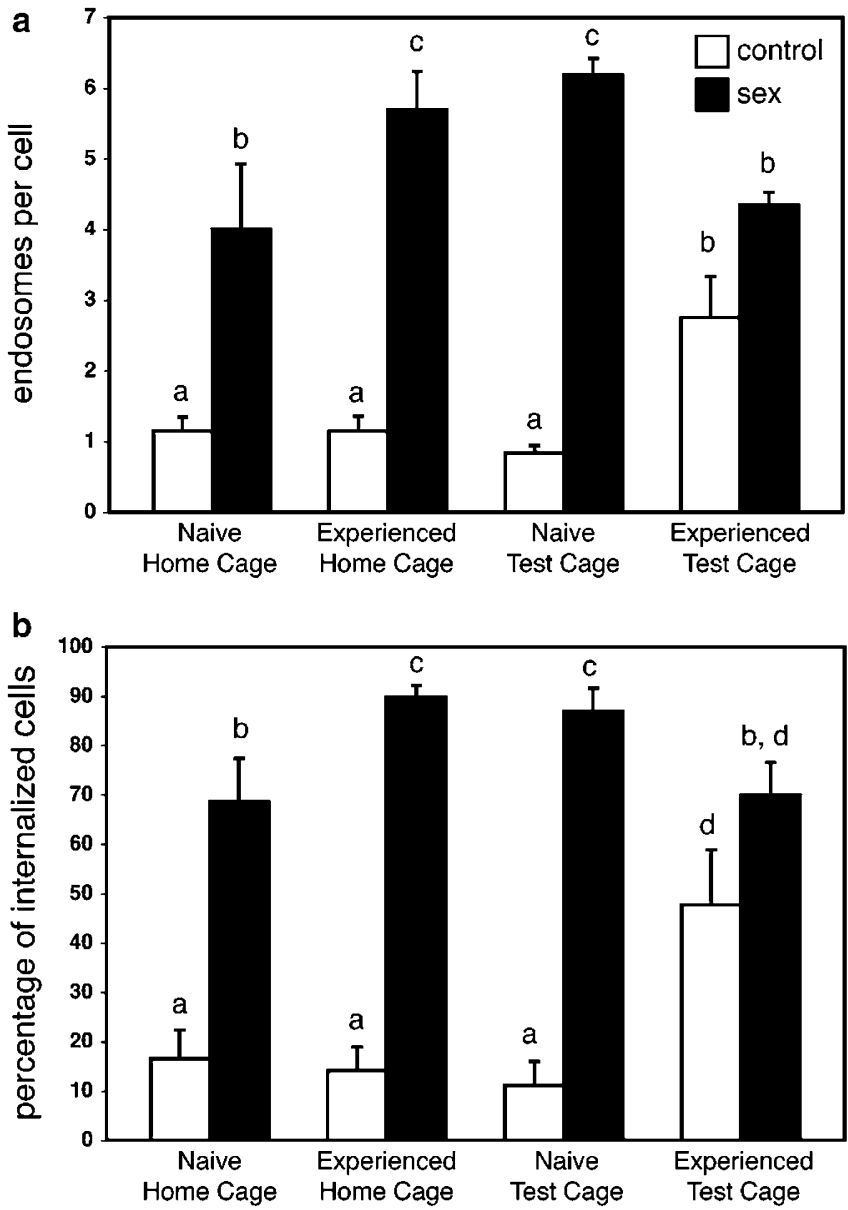

Figure 5 MOR internalization in VTA neurons. (a) Numbers of MOR-IR endosome-like particles per cell. Mean numbers \pm SEM of MOR-IR endosome-like particles per cell per behavioral group. (b) Percentages of cells that show MOR internalization. Mean percentages \pm SEM of VTA MOR-IR cells that contain three or more endosomes per behavioral group. Solid bars represent groups that mated on the test day, and open bars represent control groups that did not mate on the test day. The statistical relationship between the groups is indicated by lower-case letters; groups that share a common letter do not differ significantly.

Table 2 Summary of Sexual Behavior During the Final Pre-Test Mating Session

\begin{tabular}{lllllll}
\hline Group & ML & IL & EL & \#M & \#I & \#E \\
\hline Home cage & $27.9 \pm 8.4$ & $43.0 \pm 8.1$ & $744.9 \pm 108.0$ & $15.1 \pm 3.0$ & $13.8 \pm 2.8$ & $4.5 \pm 0.3$ \\
Test cage & $29.8 \pm 11.2$ & $36.1 \pm 12.9$ & $717.4 \pm 101.2$ & $13.6 \pm 1.3$ & $11.8 \pm 0.5$ & $4.8 \pm 0.2$
\end{tabular}

The mean \pm SEM for latencies (in seconds) to mount (ML), intromission (IL) and ejaculation (EL), the numbers of mounts (\#M) and intromissions (\#IM) during the final pre-test mating session, as well as the total number of ejaculations over the course of the entire training period (\#E) are presented. No significant differences were observed between groups. 
Table 3 Summary of Sexual Behavior on the Test Day

\begin{tabular}{|c|c|c|c|c|c|}
\hline Group & ML & IL & EL & $\# M$ & $\# \mathbf{I}$ \\
\hline Naïve home cage & $133.3 \pm 3 a, b$ & $237.8 \pm 66.1 \mathrm{a}$ & $2245.0 \pm 469.4 a, c$ & $51.5 \pm 14.1 \mathrm{a}, \mathrm{b}$ & $15.0 \pm 1.5 \mathrm{a}$ \\
\hline Exp. home cage & $34.8 \pm 22.9 a, b$ & $47.8 \pm 18.7 a$ & $1048.8 \pm 296.5 a, b$ & $15.3 \pm 3.3 \mathrm{a}$ & $14.5 \pm 1.6 \mathrm{a}$ \\
\hline Naive test cage & $290.3 \pm 158.2 b$ & $748.8 \pm 289.6 b$ & $2702.5 \pm 594.6 a, c$ & $66.0 \pm 18.3 b$ & $10.8 \pm 1.1 \mathrm{a}$ \\
\hline Exp. test cage & $9.3 \pm 3.8 a$ & $34.8 \pm 12.5 a$ & $521.0 \pm 166.9 b$ & $26.0 \pm 10.4 a$ & $13.0 \pm 1.7 \mathrm{a}$ \\
\hline
\end{tabular}

The mean \pm SEM (in seconds) for latencies to mount (ML), intromission (IL), and ejaculation (EL) and the numbers of mounts (\#M) and intromissions (\#IM) are presented. The statistical relationship between the groups is indicated by lower-case letters; groups that share a common letter do not differ significantly.

that MOR internalization was significantly increased in experienced males that had been placed in the environment in which they received prior sexual experience, but did not mate on the test day when compared to all other unmated control groups (Figure 5a, open bars; $p<0.05$ ). Sexual behavior also significantly increased the percentage of MOR-IR neurons that showed internalization $\left(\mathrm{F}_{(1,23)}=136.312 ; p<0.0001\right)$. In particular, a greater proportion of internalized MOR-IR neurons was observed in males that mated on the test day compared to their unmated controls (Figure 5b, filled $v s$ open bars; $p<0.03$ ), and in sexually experienced males that were exposured to the sex-related environment, but did not mate compared to all other unmated control groups (Figure 5b, open bars; $p<0.01)$.

\section{Fos Expression in Dopamine Neurons}

Sexual behavior and exposure to the sex-related environment resulted in activation of dopamine neurons throughout the VTA (Figures 4e, f and 6). There was a significant effect of mating on the percentage of $\mathrm{TH}$ cells expressing Fos throughout the VTA $\left(\mathrm{F}_{(1,24)}=99.774 ; p<0.0001\right)$. Post $h o c$ analysis indicated significant mating-induced increases in Fos expression in naive males that mated in either home or test cage compared to their unmated controls, and in experienced males that mated in the home cage compared to their unmated controls (Figure $6, p<0.0001$ ). In addition, a two-way interaction between mating and environment was observed $\left(\mathrm{F}_{(1,24)}=12.479 ; p=0.0017\right)$. Post hoc analysis indicated that the percentage of activated TH cells was significantly increased in experienced unmated control males that were exposed to the environment in which they received prior sexual experience compared to all other unmated control groups (Figure $6, p<0.001$ ). Interestingly, mating did not further increase the percentages of activated $\mathrm{TH}$ neurons in experienced males, relative to the cueinduced activation observed in the unmated controls. Overall, the percentages of sex/environment-activated $\mathrm{TH}$ neurons appeared higher in the rostral levels of the VTA compared to the caudal levels, although this was not statistically analyzed (Table 4 ).

\section{Fos Expression in Nondopaminergic Neurons}

Although sexual behavior and sex-related cues induced Fos expression in TH neurons, the majority (80-90\%) of Fos-IR neurons in the VTA did not express TH. Analysis of Fos expression in these nondopaminergic neurons revealed a

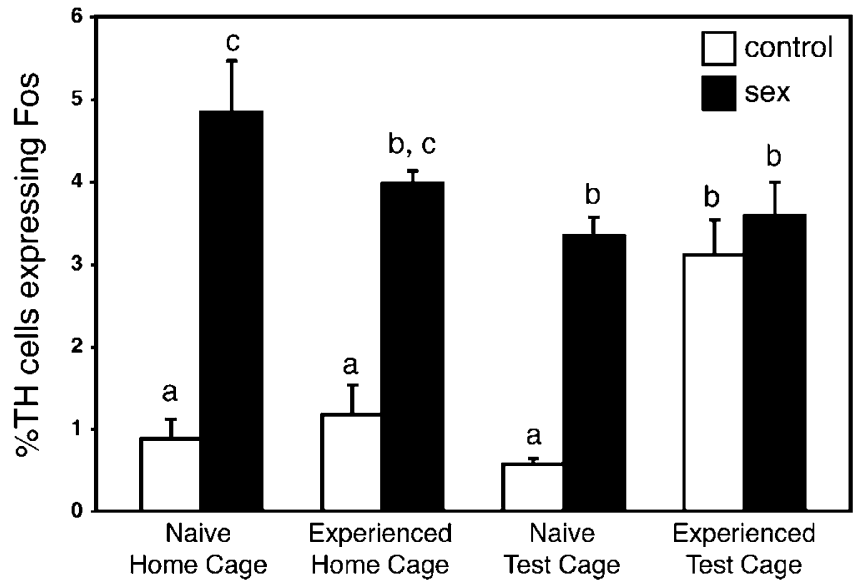

Figure 6 Percentages of TH-IR cells that are Fos-IR in the VTA. Mean percentages \pm SEM of TH-IR cells that are Fos-IR averaged over four rostral-to-caudal levels. Solid bars represent groups that mated on the test day, and open bars represent control groups that did not mate on the test day. The statistical relationship between the groups is indicated by lowercase letters; groups that share a common letter do not differ significantly.

Table 4 Percentage of TH Cells Expressing Fos

\begin{tabular}{lllll}
\hline Group & \multicolumn{1}{c}{ Rostral } & Middle- I & Middle-2 & Caudal \\
\hline Naive home cage & & & \\
Control & $2.73 \pm 0.76 \mathrm{a}$ & $1.03 \pm 0.36 \mathrm{a}, \mathrm{c}$ & $0.68 \pm 0.30 \mathrm{a}$ & $0.20 \pm 0.12 \mathrm{a}$ \\
Sex & $14.54 \pm 2.07 \mathrm{~b}, \mathrm{c}$ & $5.35 \pm 0.10 \mathrm{~b}$ & $3.19 \pm 0.90 \mathrm{~b}$ & $1.94 \pm 0.36 \mathrm{~b}$
\end{tabular}

\begin{tabular}{|c|c|c|c|c|}
\hline \multicolumn{5}{|c|}{ Exp. home cage } \\
\hline Control & $5.76 \pm 1.21 \mathrm{a}$ & $1.12 \pm 0.45 a, c$ & $0.42 \pm 0.42 \mathrm{a}$ & $0.27 \pm 0.17 a$ \\
\hline Sex & $12.64 \pm 1.46 c, d$ & $5.80 \pm 0.66 b$ & $2.16 \pm 0.4 \mathrm{lb}$ & $0.79 \pm 0.27$ \\
\hline
\end{tabular}

$\begin{array}{lllll}\text { Naive test cage } & & & \\ \text { Control } & 2.91 \pm 0.39 \mathrm{a} & 0.74 \pm 0.11 \mathrm{a} & 0.20 \pm 0.20 \mathrm{a} & 0.00 \pm 0.00 \mathrm{a} \\ \text { Sex } & 9.09 \pm 1.27 \mathrm{~d}, \mathrm{~b} & 5.29 \pm 0.37 \mathrm{~b} & 1.86 \pm 0.38 \mathrm{~b} & 0.65 \pm 0.18 \mathrm{a}\end{array}$

Exp. test cage
$\begin{array}{lllll}\text { Control } & 11.27 \pm 2.66 \mathrm{~b}, \mathrm{c}, \mathrm{d} & 2.24 \pm 0.58 \mathrm{~b}, \mathrm{c} & 2.71 \pm 0.55 \mathrm{~b} & 1.38 \pm 0.57 \mathrm{~b} \\ \text { Sex } & 7.14 \pm 1.20 \mathrm{~b}, \mathrm{~d} & 4.56 \pm 0.78 \mathrm{~b} & 2.78 \pm 0.45 \mathrm{~b} & 1.98 \pm 0.58 \mathrm{~b}\end{array}$

The mean percentages of TH cells expressing Fos at four levels through the VTA $($ mean \pm SEM) are presented. The statistical relationship between the experimental groups is indicated by lower-case letters; groups that share a common letter do not differ significantly. Comparisons were made between experimental groups within each rostrocaudal level. 
similar induction pattern as in $\mathrm{TH}$ neurons (Figure 7). Specifically, a significant effect of mating on Fos expression was observed $\left(\mathrm{F}_{(1,24)}=40.093, p<0.0001\right)$, and significant mating-induced increases in numbers of Fos-IR neurons were present in the naïve and experienced males that mated in the home cages compared to their unmated controls, as well as in the naïve males that mated in the test cage compared to their unmated controls (Figure $7, p<0.006$ ). Moreover, there was a significant interaction between mating and environment $\left(\mathrm{F}_{(1,24)}=5.288, p=0.0305\right)$, and a significant increase in Fos expression was observed in

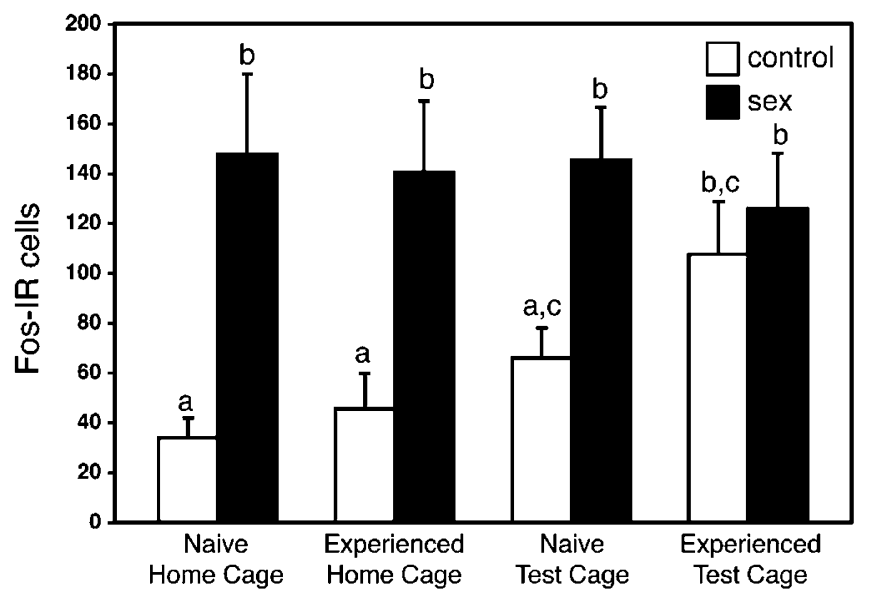

Figure 7 Numbers of nondopaminergic cells that are Fos-IR in the VTA. Mean numbers \pm SEM of Fos-IR cells that are not TH-IR averaged over four rostral-to-caudal levels. Solid bars represent groups that mated on the test day, and open bars represent control groups that did not mate on the test day. Solid bars represent groups that mated on the test day, and open bars represent control groups that did not mate on the test day. The statistical relationship between the groups is indicated by lower-case letters; groups that share a common letter do not differ significantly. experienced unmated males that were placed in the environment in which they had received prior sexual experience compared to all other unmated control groups (Figure $7, p<0.02$ ). Sexual behavior in experienced males that mated in the test cage did not further increase the level of Fos expression compared to their unmated controls. Analysis of Fos expression in each of the separate rostrocaudal levels of the VTA revealed a similar pattern of Fos expression described above for the total VTA. However, the majority of Fos-IR neurons were observed in the rostral levels of the VTA (Table 5), although differences in Fos expression between rostrocaudal levels were not statistically analyzed.

\section{Fos Expression in the NAc}

Sexual behavior and exposure to the sex-related environment resulted in neuronal activation in the NAc (Figure 8). There was a significant effect of mating on the number of cells expressing Fos in both the NAc Core $\left(\mathrm{F}_{(1,24)}=457.265\right.$, $p<0.0001)$ and NAc Shell $\left(\mathrm{F}_{(1,24)}=234.159, p<0.0001\right)$. In the NAc Core, a significant mating-induced increase in the numbers of activated neurons was present in all males that mated on the test day compared to their controls (Figure 8b, $p<0.0001)$. In addition, a two-way interaction was observed between mating and environment $\left(\mathrm{F}_{(1,24)}=3.244\right.$, $p=0.0294)$. Post hoc analysis revealed that the number of activated cells was significantly increased in experienced unmated control males that were exposed to the environment in which they received prior sexual experience (Figure $8 \mathrm{~b}, p<0.002$ ). Similarly, in the NAc shell, a significant mating-induced increase in the numbers of activated neurons was present in all males that mated on the test day compared to their controls (Figure $8 \mathrm{a}, p<0.0001$ ). In addition, a two-way interaction was observed between mating and environment $\left(\mathrm{F}_{(1,24)}=8.725 ; p=0.0069\right)$. Post

Table 5 Fos Expression in Nondopaminergic Neurons

\begin{tabular}{|c|c|c|c|c|}
\hline Group & Rostral & Middle-I & Middle-2 & Caudal \\
\hline \multicolumn{5}{|c|}{ Naive home cage } \\
\hline Control & $68.50 \pm 8.31 \mathrm{a}$ & $48.25 \pm 16.90 \mathrm{a}$ & $15.5 \pm 5.55 a$ & $3.5 \pm 1.85 a$ \\
\hline Sex & $313.75 \pm 33.5 \mathrm{lb}$ & $170.75 \pm 61.89 b$ & $78.75 \pm 11.5 \mathrm{Ib}$ & $27.00 \pm 8.27 b$ \\
\hline \multicolumn{5}{|c|}{ Exp. home cage } \\
\hline Sex & $296.75 \pm 37.95 b$ & $173.00 \pm 8.8 \mathrm{Ib}$ & $67.00 \pm 12.28 b$ & $25.00 \pm 5.45 a, b$ \\
\hline \multicolumn{5}{|c|}{ Naive test cage } \\
\hline Control & $115.00 \pm 17.44 a$ & $92.50 \pm 17.49 a, b$ & $49.00 \pm 4.81 \mathrm{l}, \mathrm{c}$ & $7.25 \pm 0.75 a$ \\
\hline Sex & $244.25 \pm 42.14 b$ & $174.75 \pm 16.91 \mathrm{~b}$ & $104.25 \pm 15.00 \mathrm{~b}$ & $57.25 \pm 9.50 c$ \\
\hline
\end{tabular}

The numbers of Fos-IR cells not expressing TH at four levels through the VTA (mean \pm SEM) are presented. The statistical relationship between the experimental groups is indicated by lower-case letters; groups that share a common letter do not differ significantly. Comparisons were made between experimental groups within each rostrocaudal level. 

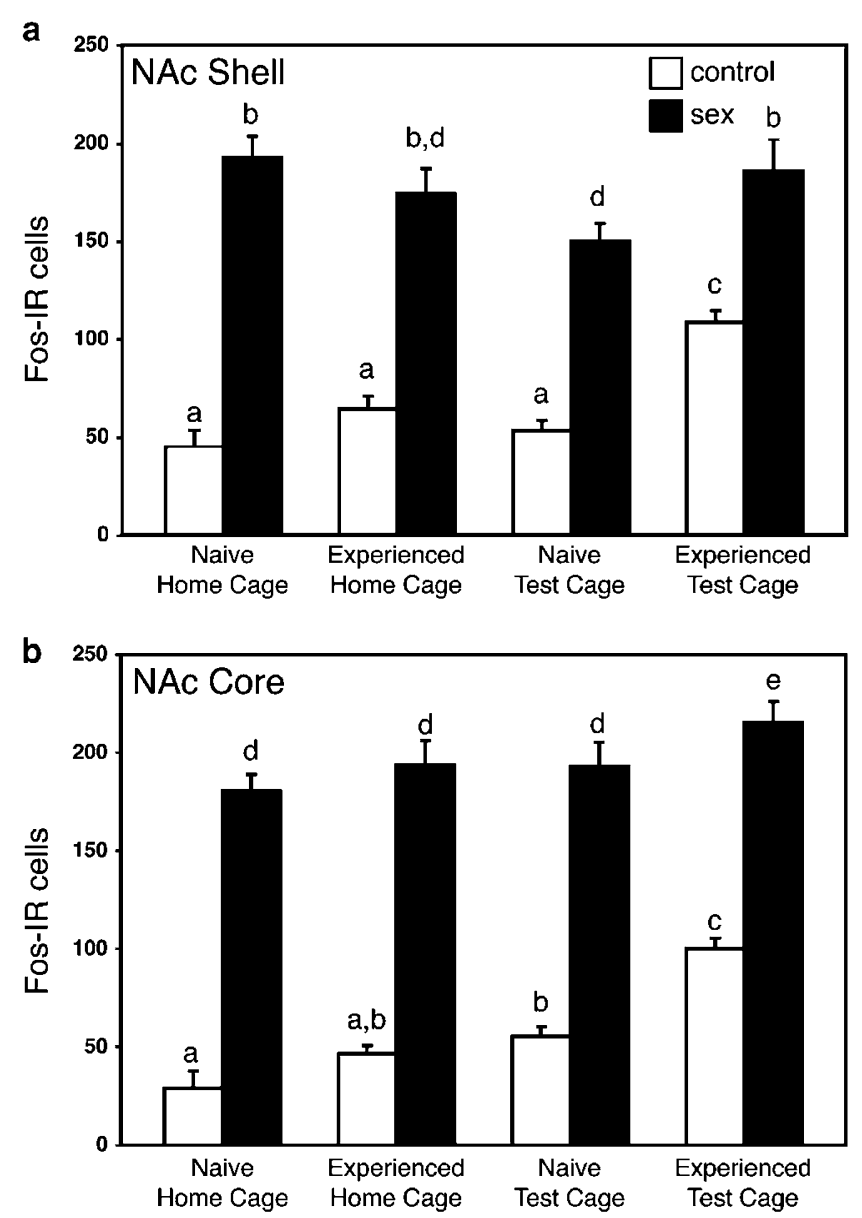

Figure 8 Numbers of Fos-IR cells in the NAc. Mean numbers \pm SEM of Fos-IR cells in the NAc shell (a) or NAc core (b) averaged over three rostral-to-caudal levels. Solid bars represent groups that mated on the test day, and open bars represent control groups that did not mate on the test day. The statistical relationship between the groups is indicated by lowercase letters; groups that share a common letter do not differ significantly.

hoc analysis revealed that the number of activated cells was significantly increased in experienced control males that were exposed to the environment in which they received prior sexual experience compared to all the other unmated control groups (Figure $8 \mathrm{a}, p<0.005$ ). Results from all the three rostrocaudal levels are presented in Table $6 a$ and $b$.

\section{DISCUSSION}

The current study provides the first direct anatomical evidence that both MOR and dopaminergic neurons in the VTA are activated during sexual behavior. These results support previous findings by microdialysis and pharmacological studies suggesting that the mesolimbic DA pathway is activated during sexual behavior. First, it was demonstrated that mating results in ligand-induced activation of MOR in VTA neurons, suggesting that activation of the VTA is mediated by endogenous opioids released during sexual behavior. Second, mating was shown to result in the activation of DA neurons in the VTA, potentially contributing to DA release in the NAc. Indeed, a similar pattern of
Table 6 Fos Expression in (a) NAc core, ${ }^{a}$ (b) NAc shell ${ }^{b}$

\begin{tabular}{lrrr}
\hline Group & Rostral & Middle & Caudal \\
\hline Fos expression in NAc core & & \\
Naive home cage & & \\
Control & $29.00 \pm 11.50 \mathrm{a}$ & $28.00 \pm 8.95 \mathrm{a}$ & $30.00 \pm 7.7 \mathrm{la}$ \\
Sex & $176.75 \pm 21.8 \mathrm{lb}$ & $183.00 \pm 9.33 \mathrm{~b}$ & $181.75 \pm 6.4 \mathrm{lb}$
\end{tabular}

$\begin{array}{lrrr}\text { Exp. home cage } & & & \\ \text { Control } & 51.75 \pm 8.34 \mathrm{a}, \mathrm{c} & 41.50 \pm 0.87 \mathrm{a} & 46.00 \pm 6.4 \mathrm{la} \\ \text { Sex } & 195.00 \pm 21.4 \mathrm{Ib} & 189.50 \pm 18.4 \mathrm{Ib} & 195.50 \pm 8.9 \mathrm{lb}\end{array}$

$\begin{array}{lccc}\text { Naive test cage } & & & \\ \text { Control } & 59.25 \pm 5.75 a, c & 52.00 \pm 4.98 a & 55.00 \pm 8.16 a \\ \text { Sex } & 207.00 \pm 16.39 b & 176.75 \pm 17.10 b & 194.25 \pm 10.53 b\end{array}$

$\begin{array}{llrr}\text { Exp. test cage } & & & \\ \text { Control } & 106.25 \pm 5.31 \mathrm{c} & 99.75 \pm 6.25 \mathrm{c} & 94.25 \pm 6.93 \mathrm{c} \\ \text { Sex } & 223.75 \pm 29.3 \mathrm{lb} & 184.50 \pm 8.0 \mathrm{lb} & 237.25 \pm 11.44 \mathrm{~d}\end{array}$

Fos expression in NAc shell

Naive home cage

$\begin{array}{lccc}\text { Control } & 35.75 \pm 11.02 a & 45.00 \pm 9.19 a & 54.50 \pm 5.28 a \\ \text { Sex } & 179.50 \pm 9.35 b & 171.25 \pm 17.76 b & 226.75 \pm 16.42 b\end{array}$

$\begin{array}{lccc}\text { Exp. home cage } & & & \\ \text { Control } & 45.25 \pm 9.53 \mathrm{a} & 62.75 \pm 8.72 \mathrm{a} & 85.00 \pm 3.31 \mathrm{a} \\ \text { Sex } & 154.25 \pm 10.21 \mathrm{~b} & 161.00 \pm 11.51 \mathrm{~b} & 206.50 \pm 24.46 \mathrm{~b}\end{array}$
Naive test cage

$\begin{array}{lcrc}\text { Control } & 62.75 \pm 6.09 a, c & 45.75 \pm 8.86 a & 51.75 \pm 9.54 a \\ \text { Sex } & 127.00 \pm 15.62 b, c & 145.00 \pm 9.34 b & 178.25 \pm 10.34 b\end{array}$

Exp. test cage

$\begin{array}{lccc}\text { Control } & 88.00 \pm 1.87 c & 107.00 \pm 9.51 c & 131.25 \pm 10.36 c \\ \text { Sex } & 188.50 \pm 32.99 b & 170.00 \pm 7.82 b & 199.25 \pm 19.14 b\end{array}$

aThe numbers of Fos-IR cells not expressing TH, at three levels through the NAc Core (mean \pm SEM) are presented. The statistical relationship between the experimental groups is indicated by lower-case letters; groups that share a common letter do not differ significantly. Comparisons were made between experimental groups within each rostrocaudal level.

'The numbers of Fos-IR cells not expressing $\mathrm{TH}$ at four levels through the NAc shell are presented. The statistical relationship between the experimental groups is indicated by lower-case letters; groups that share a common letter do not differ significantly. Comparisons were made between experimental groups within each rostrocaudal level.

mating-induced activation was observed in NAc neurons, possibly due to DA release. Finally, sexual behavior resulted in activation of nondopaminergic neurons in the VTA. Interestingly, all of these effects were also observed in response to spatial and tactile environmental cues associated with prior sexual experiences. Taken together, these data support involvement of the mesolimbic pathway in male sexual behavior and reward. 
The present study marks the first demonstration of MOR activation in the VTA by either a natural behavior or environmental cues. Others have used similar techniques to visualize MOR activation in other areas of the brain and spinal cord, in response to exogenously applied opioids (Keith et al, 1998; Trafton et al, 2000) and estrogen (Eckersell et al, 1998; Sinchak and Micevych, 2001). Recent studies from our laboratory have shown that sexual behavior causes MOR internalization in the medial preoptic nucleus of the hypothalamus in male rats (Coolen et al, 2003). In the present study, MOR internalization was detected in the VTA following both sexual behavior and sex-associated environmental cues, suggesting that endogenous opioid peptides are released in response to these stimuli. Although this technique provides a useful marker for endogenous activation of MOR, it is an indirect marker for opioid release. Furthermore, the specific opioid ligand involved in MOR activation in VTA has not been identified. Anatomical studies show both beta-endorphin (Mansour et al, 1988) and enkephalin (Johnson et al, 1980; Fallon and Leslie, 1986) terminals in the VTA, and pharmacological evidence shows that both of these peptides can activate the mesolimbic DA system (Broekkamp et al, 1979; Stinus et al, 1980; Dauge et al, 1992). In addition, recent reports have indicated the presence of the highly MOR-specific ligands endomorphin-1 and -2 in the VTA (Greenwell et al, 2002). Although the present study focused exclusively on MOR, it is possible that other opioid receptors are also involved in the sex-induced activation of the mesolimbic system. Autoradiographic studies show that delta and kappa opioid receptors are present in the VTA, albeit at much lower densities compared to MOR (Mansour et al, 1987, 1988; Dilts and Kalivas, 1990; Xia and Haddad, 1991). Furthermore, delta agonists infused into the VTA are 100-1000 times less potent at stimulating DA release in the NAc, while kappa agonists fail to do so altogether (Devine et al, 1993), suggesting that sex-induced activation of the mesolimbic DA pathway occurs primarily via MOR activation.

The anatomical data in the present study further support the evidence that MOR indirectly activates mesolimbic dopamine neurons via inhibition of GABA interneurons. Using confocal microscopy, MOR were observed on both GABAergic cell bodies and fibers in close apposition to GABAergic neurons. These fibers had the appearance of boutons, indicative of axon terminals; hence MOR appear to be located presynaptic to GABAergic cell bodies. These findings are in agreement with previous observations that MOR in the VTA are not located on DA neurons (Garzon and Pickel, 2001), suggesting an indirect relationship. Furthermore, pharmacological studies have shown that MOR agonists inhibit GABA neuron firing, stimulate DA neuron firing, and increase DA release into the NAc (Matthews and German, 1984; Leone et al, 1991; Johnson and North, 1992). In the current study, analysis of matinginduced internalization was restricted to the rostral portion of the VTA, where the majority of MOR-containing cell bodies are located. In this region, $79 \%$ of the MORcontaining cell bodies were GABAergic, suggesting that most of the MOR internalization was in GABAergic neurons. However, it is unclear if all GABAergic neurons we observed in the VTA are local interneurons, since GABA neurons also send projections to the NAc or prefrontal cortex (Carr and Sesack, 2000). Nonetheless, these results provide further evidence that, during natural motivated behavior, MOR ligands inhibit GABAergic interneurons, resulting in activation of dopaminergic neurons in the VTA and release of DA in the NAc.

The present study also demonstrates sex-induced activation of DA neurons in the VTA. Although it was not shown directly that MOR activation caused the activation of DA neurons, the same pattern of activation was observed in both systems - that is, activation by both sexual behavior and sex-related environmental cues - suggesting that the neural activation in the MOR and DA systems may be correlated. It is currently unknown if the activated VTA DA neurons project to the NAc. However, anatomical evidence has shown that the NAc is the major target of the DA projection from the VTA (Swanson, 1982). Moreover, it has been shown that morphine-induced Fos-IR in the NAc is a result of opioid action in the VTA (Bontempi and Sharp, 1997). The present data further support this model and indicate that endogenous opioids released into the VTA initiate the activation of this mesolimbic pathway during male sexual behavior. Furthermore, sex- and cue-induced Fos expression was observed in both the NAc core and shell. These subregions of the NAc differ in their histochemical characteristics and connectivity with other components of the circuitry mediating motivation and reward (Heimer et al, 1997; Kelley, 1999; Zahm, 1999). In particular, the NAc Core possesses similarities to the dorsal striatum, and sends projections to classic basal ganglia output structures, including the ventral pallidum, subthalamic nucleus, and substantia nigra. Conversely, the NAc shell sends projections mainly to limbic structures such as the VTA, lateral hypothalamus, and brainstem autonomic centers (Heimer et al, 1991; Zahm and Brog, 1992). Thus, sexual behavior and sex-associated cues result in the activation of mesolimbic components related to voluntary motor function as well as motivation and emotion.

Although the present results show that key components of the mesolimbic dopamine pathway are activated during male sexual behavior, it is not clear when during the behavior this activation occurs. In fact, it is possible that activation of this system may occur at different times during the behavior in sexually naïve $v s$ experienced animals. Specifically, the VTA and NAc were activated in response to sex-related environmental cues, in the absence of interaction with a female partner, which suggests that opioids are released during the appetitive phase of the behavior. This reasoning is in agreement with Shultz's studies showing dopaminergic activity in the VTA of monkeys when reward is anticipated (Schultz, 2001). In the present study, the mating environment appears to act as a conditioned stimulus predicting the sexual reward. Interestingly, not only were dopamine neurons activated by the predicted reward, but also activation of MOR was observed. Hence, endogenous opioids in the VTA may lead to the activation of this circuit in response to reward-predicting environmental cues. In contrast, Schultz (2001) illustrated that when reward was not predicted, dopamine neurons were activated during presentation of the reward. In agreement with this hypothesis, it is possible that, in sexually naïve animals, activation of the mesolimbic dopamine pathway occurs during the unpredicted sexual 
reward. Previous reports have indicated that ejaculation is the most rewarding component of sexual behavior (Agmo and Berenfeld, 1990; Lopez et al, 1999). However, microdialysis studies have shown that odors of a receptive female can induce DA release in the NAc, even in sexually naïve males (Wenkstern et al, 1993). It is currently unclear if exposure to female odors has a rewarding or predictive value for sexually naïve males.

Pharmacological studies suggest that the mesolimbic system involved in the motivational aspects of sexual behavior. MOR agonists infused directly into the VTA facilitate sexual behavior (Mitchell and Stewart, 1990). Conversely, naloxone decreases the number of anticipatory level changes in a bilevel chamber, a measure of sexual motivation (van Furth and van Ree, 1996). 6-Hyroxydopamine (6-OHDA) lesions and DA antagonists in the NAc cause similar decreases in performance on this test (van Furth et al, 1995). Furthermore, 6-OHDA lesions of the NAc delay the onset of sexual behavior and impair noncontact erection in male rats, suggesting that DA is involved in sexual arousal in response to external cues (Liu et al, 1998). These manipulations did not alter sexual performance, suggesting that this pathway is involved in the motivational aspects of the behavior rather than the consummatory phase. In addition, antagonists to either DA or opioid receptors inhibit the development of conditioned place preference to sexual behavior (Agmo and Berenfeld, 1990; Meisel et al, 1996).

Interestingly, we also observed that many nondopaminergic neurons in the VTA were activated by both sexual behavior and sex-related environmental cues. This suggests that pathways other than activation of DA neurons via endogenous opioids may be involved in the activation of the VTA. Indeed, other brain regions associated with reward such as the medial prefrontal cortex (mPFC) provide excitatory input to nondopaminergic neurons in the VTA (Sesack and Pickel, 1992; Carr and Sesack, 2000). Specifically, mPFC afferents project to VTA GABAergic interneurons and GABAergic mesoaccumbens projection neurons, but not to mesocortical GABAergic neurons (Carr and Sesack, 2000). Further studies are needed to investigate the connections and neurochemical phenotype of the sex-activated nondopaminergic neurons in the VTA, as well as their significance for sexual motivation and reward.

Finally, the results from the current study suggest the existence of rostrocaudal differences in sex-induced activation of the VTA, although these differences were not statistically analyzed in the present study. Interestingly, Bolanos and colleagues have recently demonstrated the possibility that distinct topographical regions within the VTA mediate generally positive $v s$ negative responses to emotional stimuli. In particular, they demonstrated that overexpression of phospholipase $\mathrm{C} \gamma 1$ (PLC $\gamma 1)$ in the rostral VTA enhances preference for morphine and sucrose, while PLC $\gamma 1$ overexpression in the caudal VTA decreases reward preference and increases sensitivity to aversive stimuli (Bolanos et al, 2003). In agreement, the results from the present study suggest that the rostral, but not caudal, VTA may mediate sexual motivation and reward.

In conclusion, the current study demonstrates activation of the mesolimbic system during a natural motivated behavior - male sexual behavior. Specifically, activation of this system is related to mating behavior as well as environmental cues associated with prior sexual experiences. The mesolimbic system is intimately involved in drug abuse - a 'nonnatural' motivated behavior (Wise, 1996). By studying the function of this system under natural conditions, we may gain a better understanding of its role in drug addiction.

\section{ACKNOWLEDGEMENTS}

This research was supported by the National Institutes of Health Grants DA05988 (MEB), DA14591 (LMC), DA09444 (LY), and DA13471 (LY).

\section{REFERENCES}

Agmo A, Berenfeld R (1990). Reinforcing properties of ejaculation in the male rat: role of opioids and dopamine. Behav Neurosci 104: $177-182$.

Agmo A, Gomez M (1993). Sexual reinforcement is blocked by infusion of naloxone into the medial preoptic area. Behav Neurosci 107: 812-818.

Bolanos CA, Perrotti LI, Edwards S, Eisch AJ, Barrot M, Olson VG et al (2003). Phospholipase Cgamma in distinct regions of the ventral tegmental area differentially modulates mood-related behaviors. J Neurosci 23: 7569-7576.

Bontempi B, Sharp FR (1997). Systemic morphine-induced Fos protein in the rat striatum and nucleus accumbens is regulated by mu opioid receptors in the substantia nigra and ventral tegmental area. J Neurosci 17: 8596-8612.

Broekkamp CL, Phillips AG, Cools AR (1979). Stimulant effects of enkephalin microinjection into the dopaminergic A10 area. Nature 278: 560-562.

Carr DB, Sesack SR (2000). Projections from the rat prefrontal cortex to the ventral tegmental area: target specificity in the synaptic associations with mesoaccumbens and mesocortical neurons. J Neurosci 20: 3864-3873.

Childress A, Ehrman R, McLellan AT, O’Brien C (1988). Conditioned craving and arousal in cocaine addiction: a preliminary report. NIDA Res Monogr 81: 74-80.

Coolen LM, Fitzgerald ME, Wells AB, Yu L, Lehman MN (2003). Activation of $\mathrm{mu}$ opioid receptors in the medial preoptic area following copulation in male rats. (in press).

Damsma G, Pfaus JG, Wenkstern D, Phillips AG, Fibiger HC (1992). Sexual behavior increases dopamine transmission in the nucleus accumbens and striatum of male rats: comparison with novelty and locomotion. Behav Neurosci 106: 181-191.

Dauge V, Kalivas PW, Duffy T, Roques BP (1992). Effect of inhibiting enkephalin catabolism in the VTA on motor activity and extracellular dopamine. Brain Res 599: 209-214.

Devine DP, Leone P, Pocock D, Wise RA (1993). Differential involvement of ventral tegmental $\mathrm{mu}$, delta and kappa opioid receptors in modulation of basal mesolimbic dopamine release: in vivo microdialysis studies. J Pharmacol Exp Ther 266: $1236-1246$.

Dilts RP, Kalivas PW (1990). Autoradiographic localization of delta opioid receptors within the mesocorticolimbic dopamine system using radioiodinated [2-D-penicillamine, 5-D-penicillamine]enkephalin (125I-DPDPE). Synapse 6: 121-132.

Duvauchelle CL, Ikegami A, Castaneda E (2000). Conditioned increases in behavioral activity and accumbens dopamine levels produced by intravenous cocaine. Behav Neurosci 114: $1156-1166$. 
Eckersell CB, Popper P, Micevych PE (1998). Estrogen-induced alteration of mu-opioid receptor immunoreactivity in the medial preoptic nucleus and medial amygdala. J Neurosci 18: 3967-3976.

Everitt BJ, Cador M, Robbins TW (1989). Interactions between the amygdala and ventral striatum in stimulus-reward associations: studies using a second-order schedule of sexual reinforcement. Neuroscience 30: 63-75.

Everitt BJ, Fray P, Kostarczyk E, Taylor S, Stacey P (1987). Studies of instrumental behavior with sexual reinforcement in male rats (Rattus norvegicus): I. Control by brief visual stimuli paired with a receptive female. J Comp Psychol 101: 395-406.

Everitt BJ, Stacey P (1987). Studies of instrumental behavior with sexual reinforcement in male rats (Rattus norvegicus): II. Effects of preoptic area lesions, castration, and testosterone. J Comp Psychol 101: 407-419.

Fallon JH, Leslie FM (1986). Distribution of dynorphin and enkephalin peptides in the rat brain. J Comp Neurol 249: 293-336.

Garzon M, Pickel VM (2001). Plasmalemmal mu-opioid receptor distribution mainly in nondopaminergic neurons in the rat ventral tegmental area. Synapse 41: 311-328.

Greenwell TN, Zangen A, Martin-Schild S, Wise RA, Zadina JE (2002). Endomorphin-1 and -2 immunoreactive cells in the hypothalamus are labeled by fluoro-gold injections to the ventral tegmental area. International Narcotics Research Conference: Pacific Grove, CA. p 26.

Harlow E, Lane D (eds) (1988). Antibodies: A Laboratory Manual. Cold Spring Harbor Laboratory: Cold Spring Harbor, NY.

Heimer L, Alheid GF, de Olmos JS, Groenewegen HJ, Haber SN, Harlan RE et al (1997). The accumbens: beyond the core-shell dichotomy. J Neuropsychiatry Clin Neurosci 9: 354-381.

Heimer L, Zahm DS, Churchill L, Kalivas PW, Wohltmann C (1991). Specificity in the projection patterns of accumbal core and shell in the rat. Neuroscience 41: 89-125.

Hull EM, Meisel RL, Sachs BD (2002). Male sexual behavior. In: Pfaff DW, Arnold AP, Etgen AM, Fahrbach SE, Rubin RT (eds). Hormones Brain and Behavior. Elsevier Science (USA): San Diego, CA. pp 1-138.

Ikemoto S, Kohl RR, McBride WJ (1997). GABA(A) receptor blockade in the anterior ventral tegmental area increases extracellular levels of dopamine in the nucleus accumbens of rats. J Neurochem 69: 137-143.

Johnson RP, Sar M, Stumpf WE (1980). A topographic localization of enkephalin on the dopamine neurons of the rat substantia nigra and ventral tegmental area demonstrated by combined histofluorescence-immunocytochemistry. Brain Res 194: $566-571$.

Johnson SW, North RA (1992). Opioids excite dopamine neurons by hyperpolarization of local interneurons. J Neurosci 12: 483-488.

Keith DE, Anton B, Murray SR, Zaki PA, Chu PC, Lissin DV et al (1998). mu-Opioid receptor internalization: opiate drugs have differential effects on a conserved endocytic mechanism in vitro and in the mammalian brain. Mol Pharmacol 53: 377-384.

Kelley AE (1999). Functional specificity of ventral striatal compartments in appetitive behaviors. Ann NY Acad Sci 877: 71-90.

Klitenick MA, DeWitte P, Kalivas PW (1992). Regulation of somatodendritic dopamine release in the ventral tegmental area by opioids and GABA: an in vivo microdialysis study. J Neurosci 12: 2623-2632.

Leone P, Pocock D, Wise RA (1991). Morphine-dopamine interaction: ventral tegmental morphine increases nucleus accumbens dopamine release. Pharmacol Biochem Behav 39: 469-472.
Liu YC, Sachs BD, Salamone JD (1998). Sexual behavior in male rats after radiofrequency or dopamine-depleting lesions in nucleus accumbens. Pharmacol Biochem Behav 60: 585-592.

Lopez HH, Olster DH, Ettenberg A (1999). Sexual motivation in the male rat: the role of primary incentives and copulatory experience. Horm Behav 36: 176-185.

Mansour A, Khachaturian H, Lewis ME, Akil H, Watson SJ (1987). Autoradiographic differentiation of mu, delta, and kappa opioid receptors in the rat forebrain and midbrain. J Neurosci 7: $2445-2464$.

Mansour A, Khachaturian H, Lewis ME, Akil H, Watson SJ (1988). Anatomy of CNS opioid receptors. Trends Neurosci 11: 308-314.

Martinez I, Paredes RG (2001). Only self-paced mating is rewarding in rats of both sexes. Horm Behav 40: 510-517.

Matthews RT, German DC (1984). Electrophysiological evidence for excitation of rat ventral tegmental area dopamine neurons by morphine. Neuroscience 11: 617-625.

Meisel RL, Joppa MA, Rowe RK (1996). Dopamine receptor antagonists attenuate conditioned place preference following sexual behavior in female Syrian hamsters. Eur J Pharmacol 309: 21-24.

Mitchell JB, Gratton A (1991). Opioid modulation and sensitization of dopamine release elicited by sexually relevant stimuli: a high speed chronoamperometric study in freely behaving rats. Brain Res 551: 20-27.

Mitchell JB, Stewart J (1990). Facilitation of sexual behaviors in the male rat associated with intra-VTA injections of opiates. Pharmacol Biochem Behav 35: 643-650.

Ostrander MM, Badiani A, Day HE, Norton CS, Watson SJ, Akil H et al (2003). Environmental context and drug history modulate amphetamine-induced c-fos mrna expression in the basal ganglia, central extended amygdala, and associated limbic forebrain. Neuroscience 120: 551-571.

Paredes RG, Alonso A (1997). Sexual behavior regulated (paced) by the female induces conditioned place preference. Behav Neurosci 111: 123-128.

Pfaus JG, Damsma G, Nomikos GG, Wenkstern DG, Blaha CD, Phillips AG et al (1990). Sexual behavior enhances central dopamine transmission in the male rat. Brain Res 530: 345-348.

Pfaus JG, Phillips AG (1989). Differential effects of dopamine receptor antagonists on the sexual behavior of male rats. Psychopharmacology (Berl) 98: 363-368.

Pfaus JG, Phillips AG (1991). Role of dopamine in anticipatory and consummatory aspects of sexual behavior in the male rat. Behav Neurosci 105: 727-743.

Schultz W (2001). Reward signaling by dopamine neurons. Neuroscientist 7: 293-302.

Sesack SR, Pickel VM (1992). Prefrontal cortical efferents in the rat synapse on unlabeled neuronal targets of catecholamine terminals in the nucleus accumbens septi and on dopamine neurons in the ventral tegmental area. J Comp Neurol 320: 145-160.

Sinchak K, Micevych PE (2001). Progesterone blockade of estrogen activation of mu-opioid receptors regulates reproductive behavior. J Neurosci 21: 5723-5729.

Stinus L, Koob GF, Ling N, Bloom FE, Le Moal M (1980). Locomotor activation induced by infusion of endorphins into the ventral tegmental area: evidence for opiate-dopamine interactions. Proc Natl Acad Sci USA 77: 2323-2327.

Swanson LW (1982). The projections of the ventral tegmental area and adjacent regions: a combined fluorescent retrograde tracer and immunofluorescence study in the rat. Brain Res Bull 9: 321-353.

Trafton JA, Abbadie C, Marek K, Basbaum AI (2000). Postsynaptic signaling via the [mu]-opioid receptor: responses of dorsal horn neurons to exogenous opioids and noxious stimulation. J Neurosci 20: 8578-8584. 
van Furth WR, van Ree JM (1996). Sexual motivation: involvement of endogenous opioids in the ventral tegmental area. Brain Res 729: $20-28$.

van Furth WR, Wolterink G, van Ree JM (1995). Regulation of masculine sexual behavior: involvement of brain opioids and dopamine. Brain Res Brain Res Rev 21: 162-184.

Wallace BC (1989). Psychological and environmental determinants of relapse in crack cocaine smokers. J Subst Abuse Treat 6: 95-106.

Watson Jr RE, Wiegand SJ, Clough RW, Hoffman GE (1986). Use of cryoprotectant to maintain long-term peptide immunoreactivity and tissue morphology. Peptides 7: 155-159.

Wenkstern D, Pfaus JG, Fibiger HC (1993). Dopamine transmission increases in the nucleus accumbens of male rats during their first exposure to sexually receptive female rats. Brain Res 618: $41-46$.

Wise RA (1996). Neurobiology of addiction. Curr Opin Neurobiol 6: $243-251$

Xia Y, Haddad GG (1991). Ontogeny and distribution of opioid receptors in the rat brainstem. Brain Res 549: 181-193.

Zahm DS (1999). Functional-anatomical implications of the nucleus accumbens core and shell subterritories. Ann NY Acad Sci 877: 113-128.

Zahm DS, Brog JS (1992). On the significance of subterritories in the 'accumbens' part of the rat ventral striatum. Neuroscience 50: 751-767. 